\title{
Some open questions of evaluation of comfort properties of functional clothing
}

\begin{abstract}
In the paper, several relatively new aspects of testing of functional clothing are discussed, such as the effect of moisture and testing time on water vapour permeability of fabrics as well as the effect of the testing time on thermal resistance value of fabrics tested in Skin Model type testers. Also the difference between thermal resistance and thermal absorptivity of fabrics was explained. It was concluded, that there are still some unsolved problems in the above areas, which should attract the attention of textile scientists and technologists.
\end{abstract}

Keywords: clothing comfort, testing, moisture, water vapour permeability, thermal resistance, thermal absorptivity
Volume 6 Issue 4 - 2020

\section{Lubos Hes}

Technical University of Liberec, Czech Republic

Correspondence: Lubos Hes, Technical University of Liberec, 46015 Liberec, Czech Republic, Email luboshes@gmail.com

Received: July 12, 2020 | Published: July 28, 2020

\section{Introduction}

In last decades, comfort properties of functional clothing became very important aspects of their quality and that is why lot of attention is also paid to testing of thermophysiological parameters of this clothing, ${ }^{1-3}$ namely to testing of water vapour and thermal resistance of the used fabrics.

Most of these properties were and still are tested in dry state of the used fabrics. However, due to the absorbed moisture caused by accumulated sweat or rain, functional (namely sport or protective) clothing is very often used in wet state also, which can significantly reduce its thermal insulation and water vapor permeability (WVP). ${ }^{4}$ Unfortunately, just few papers were published on fabric thermal comfort in wet state, ${ }^{5-9}$ as standard WVP testing instruments type Skin model are in most cases too slow to keep the sample wet during the testing process. Moreover, there are no standards on testing of WVP of fabrics in wet state available. That is why the testing of VW permeability of fabrics in wet state is still not as common as it should be. Basic principle of this new testing method is explained in the next chapter.

Besides the effect of moisture on WV permeability of fabrics, also the effect of testing time on this property determined in Skin models was not yet properly explained in the available literature, as well as the influence of testing time on thermal resistance value of fabrics tested in Skin Model type testers.

These new aspects of testing of thermophysiological parameters of functional fabrics and clothing will be shortly described in the paper, as well as the difference between thermal resistance and thermal absorptivity of fabrics. ${ }^{10}$

\section{The effect of moisture on water vapour permeability of fabrics}

In the next lines, a recent method of determination of the effective WVP of fabrics in wet state is presented, based on the measurement of relative cooling flow $\mathrm{q}_{\mathrm{tot}}$ passing through a wet fabric placed on the measuring surface of the quick PERMETEST Skin model. This $q_{\text {tot }}$ flow consists of the relative cooling flow $\mathrm{q}_{\text {skin }}$ caused by water vapour evaporation from the human skin, and relative cooling flow $\mathrm{q}_{\mathrm{fab}}$ originated by water vapour evaporation from the wet fabric surface. Thus, the $\mathrm{q}_{\text {tot }}$ results from the relationship. ${ }^{6}$

$$
\mathrm{q}_{\text {tot }}=\mathrm{q}_{\text {skin }}+\mathrm{q}_{\text {fab }}
$$

In the next step, an impermeable foil is inserted between the wet sample and the measuring surface of the tester, and the instrument measures $\mathrm{q}_{\mathrm{fab}}$ cooling flow only. The difference between the direct measurement and the measurement with a foil inserted between the wet sample and the measuring surface of the tester then presents the required level of the relative cooling flow $\mathrm{q}_{\text {skin }}$ or effective relative WVP of fabrics in wet state. From the measurements of effective relative WVP of 30 woven fabrics differing in the used polymer and structure at 4 moisture levels follows, that the presence of moisture in fabrics reduces drastically their effective relative WVP-see the Figure 1. It is important to note, that for wet fabrics, the concept of evaporation resistance cannot be used, as the water vapour transfer processes in this case are too complex, due to the involvement of the phase changes.

From the knowledge of the moisture effect on WVP of wet fabrics results the importance of testing of comfort properties of sport and protective clothing at real conditions of their use, this time in wet state.

\section{The effect of testing time on values of water vapour resistance of semi-permeable laminated fabrics determined by skin model testers}

The process of transfer of water vapour molecule through microporous semi-permeable membranes (mostly laminated on outer fabrics) generally requires less than 3 minutes, as water vapour molecules with diameter cca 0,4 nanometres pass directly through at least hundred times larger holes in the membrane. Without any phase change, they move through the continuing pores by the Knudsen diffusion. Thus, quick water vapour resistance testers (such as PERMETEST) can determine evaporation resistance of the measured outdoor jackets within less than 5 minutes. However, if we measure jackets made of hydrophilic (nanoporous) semi-permeable laminates, then short time measurements will indicate incorrect, too high evaporation resistance values. The reason of this reduced water vapour permeability depends in special kinetics of water vapour molecules in this case. First, water vapour molecules condensate on the internal surface of the membrane, then penetrate through the macromolecular 
structure of the membrane as individual water molecules and after reaching the outer fabric surface, the water molecules evaporate. The PERMETEST can record and distinguish both phase changes, first of them generating heat and the other cooling effects. In slower Skin models, both phase changes are mutually thermally compensated and the system practically does not record any difference between the measurement of water vapour resistance of microporous and nanoporous membranes.

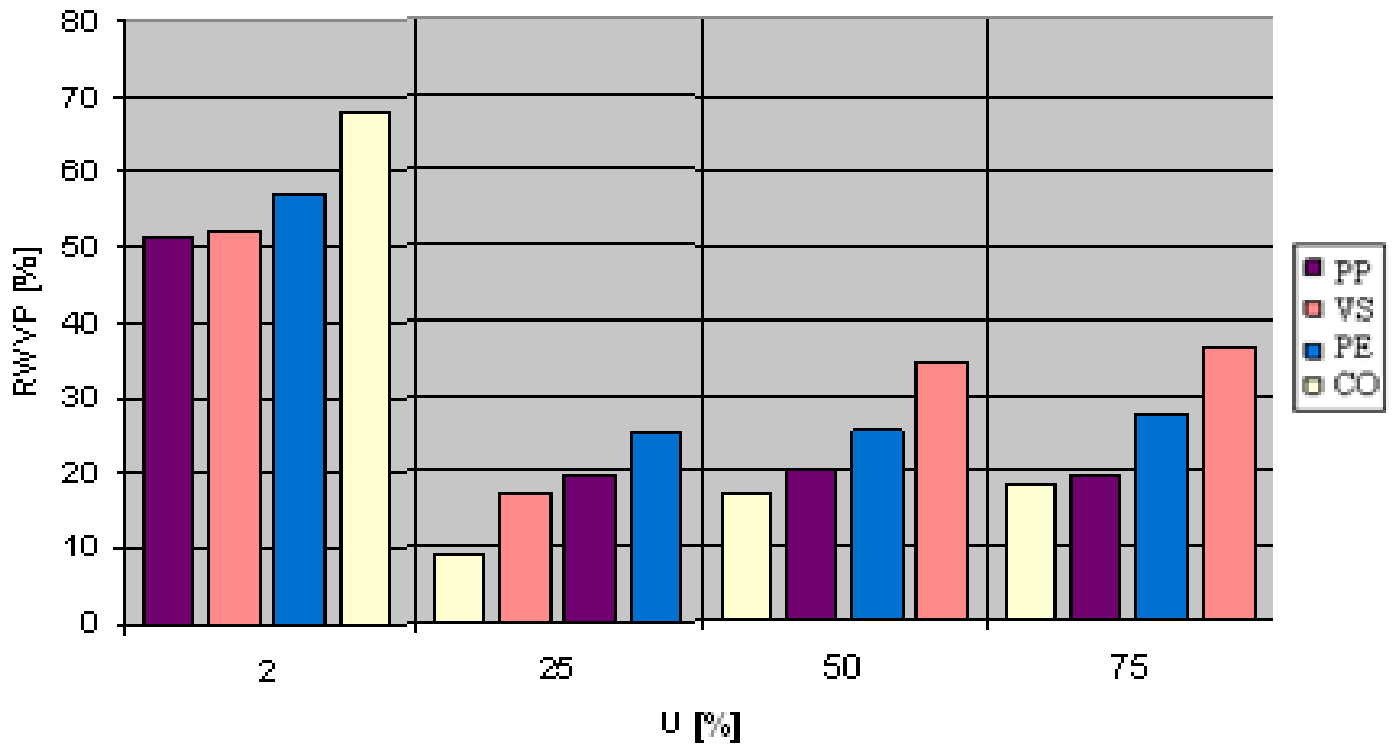

Figure I Effective relative WVP of plain woven fabrics of different polymers, square mass $70-220 \mathrm{~g} / \mathrm{m}^{2}$ (polypropylene, viscose, polyester and cotton) at various levels of their relative moisture content. ${ }^{6}$

Next practical example will illustrate the effect of time on the measurement results. A quality PATAGONIA outdoor jacket exhibited water vapour resistance of $16,5 \mathrm{~m}^{2} \mathrm{~Pa} / \mathrm{W}$, when measured by a quick PERMETEST with automatic timing. The jacket user seemed disappointed, as evaporation resistance of a good outdoor jacket should be lower than $6,0 \mathrm{~m}^{2} \mathrm{~Pa} / \mathrm{W}$. Then, the measurement time was pre-adjusted to 10 minutes and the determined evaporation resistance dropped to $5.1 \mathrm{~m}^{2} \mathrm{~Pa} / \mathrm{W}$. Next extension of time did not lead to lower Ret values.

Not only nanoporous membranes, but also wool fabrics, leather layers and some other materials, when absorbing water vapour, reveal enough heat to be recorded in a quick Skin model. Optimisation of this effect can contribute to design of more comfortable clothing.

\section{The effect of the testing time on thermal resistance value of fabrics tested in common skin models}

When measuring thermal resistance of fabrics in common skin models, the measuring surface is kept at the temperature of $35^{\circ} \mathrm{C}$, whereas the air passing along the sample in the instrument has the temperature $20{ }^{\circ} \mathrm{C}$ and relative humidity $65 \% .^{3}$ Partial pressure of water vapour at this temperature and humidity is 1519Pascals. Before inserting the sample in the instrument, the samples are usually acclimatized at the standard laboratory conditions, characterized by air temperature $20^{\circ} \mathrm{C}$ and air relative humidity $65 \%$ as well. The fabric sample, being in placed on the instrument hotplate with higher temperature, where the partial pressure of water vapour at this temperature and $100 \%$ humidity (close to the fabric surface) is 5319Pascal, due to very high difference of partial pressures gets stepwise dried, as the equilibrium moisture level in the sample at the initial lower temperature is higher than that at higher temperature. Due to strong cooling effect, the measured thermal resistance Rct is in the beginning much lower than thermal resistance of the fully dried sample. The drying process, during which the moisture content in the sample drops to the level corresponding to the new conditions, may take more than 20 minutes. Thus, the samples tested for more than 30 minutes in standard Skin models, are in some extend overdried, or better to say - their moisture corresponds to the moisture level in underwear, which is worn close to human skin. The Figure 2 shows the effect of time on thermal resistance value Rct measured in a quick Thermal resistance Rct $\left[\mathrm{m}^{2} . \mathrm{mK} / \mathrm{W}\right]$.

Skin model: The tested fabric was a $170 \mathrm{~g} / \mathrm{m}^{2}$ plain Lyocel weave. Along with the testing time, also the effect of covering the fabric surface by a thin impermeable foil was investigated. A thin foil will eliminate water vapour evaporation, despite the existing difference of WV partial pressure between the moisture in a fabric and in the drying air. Thus, even at short measurement time, the Rct values determined with a foil approximate the values achieved after long time of measurement without the covering foil. Next research will follow.

\section{What is the difference between thermal resistance and thermal absorptivity of fabrics?}

When a shop assistant wants to sell a blanket or a jacket intended for protection against cold, he may advise the client to put his hand on a fabric slightly, in order to feel how warm is it. He will try to convince the client, that this textile product would keep his body warm in the winter. However, this statement can be incorrect. If the touched fabric is thinner than one $\mathrm{mm}$, it would not provide the effective thermal insulation. What the client felt was just the temporary short time thermal contact effect, characterized by the so called thermal absorptivity. 


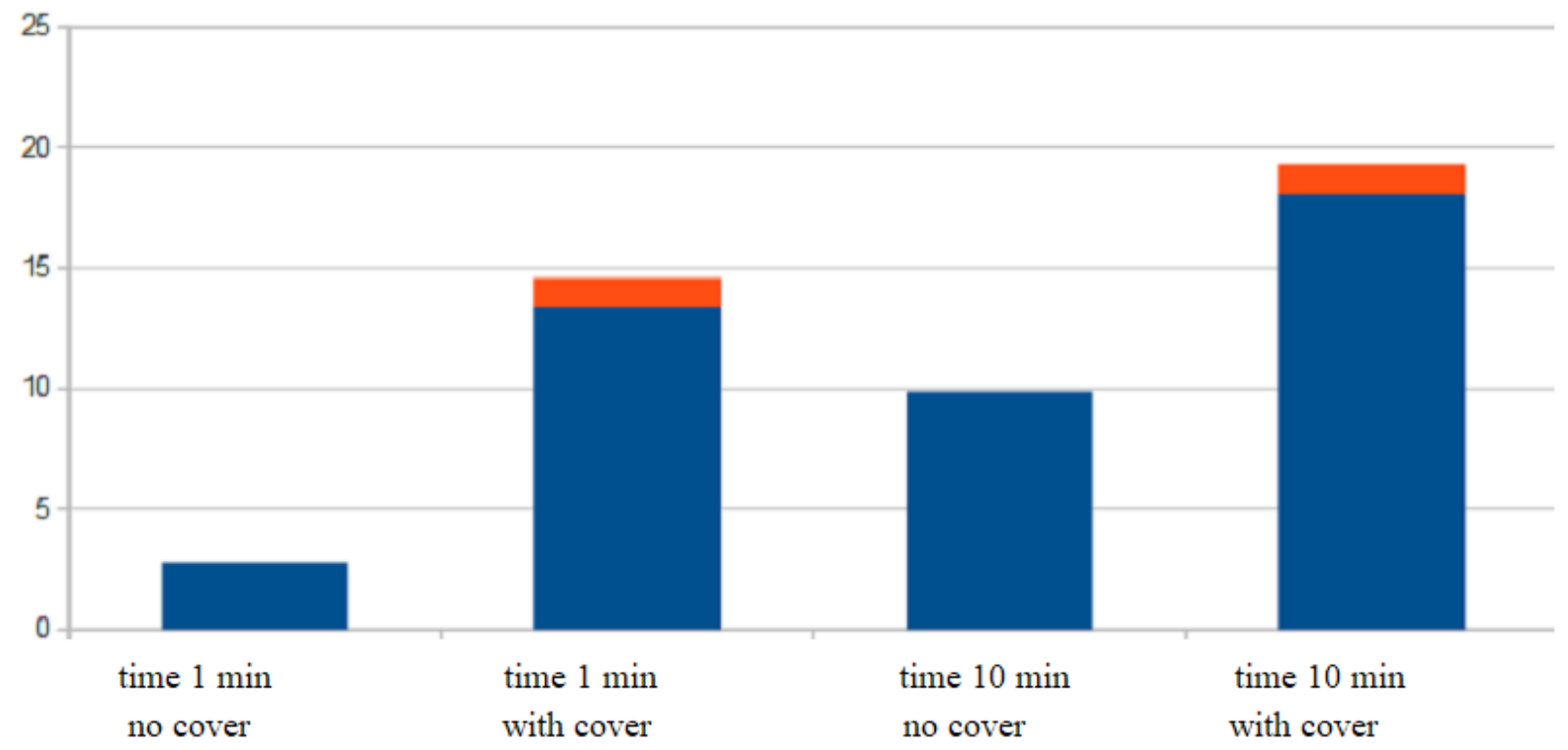

Figure 2 The effect of testing time and fabric surface cover on the determined thermal resistance of plain Lyocel woven fabrics, square mass $I 70 \mathrm{~g} / \mathrm{m}^{2}$. The red thin layer presents thermal resistance of the foil. ${ }^{4}$

Thermal absorptivity $\mathrm{b}$ of fabrics was introduced into textile area by L. Hes in $1987^{11}$ to characterise thermal feeling (heat flow level) during short contact of human skin with the fabric surface. Provided that the time of thermal contact $\tau$ between the human skin and the textile is short (a few seconds), the measured fabric can be simplified into semi-infinite homogenous mass with certain thermal capacity, $\rho c\left[\mathrm{~J} / \mathrm{m}^{3}\right]$ and initial temperature $\mathrm{t}_{2}$. Solving of the equation of an unsteady temperature field between a human skin (with constant temperature $\mathrm{t}_{1}$ ) and a fabric with respect to contact boundary condition offers a relationship, which enables to determine the heat flow q [W/ $\mathrm{m}^{2}$ ] passing through a fabric:

$$
\mathrm{q}=\mathrm{b}\left(\mathrm{t}_{1}-\mathrm{t}_{2}\right) /(\pi \tau)^{1 / 2} \mathrm{~b}=(\lambda \rho \mathrm{c})^{1 / 2}
$$

Where $\rho c\left[\mathrm{~J} / \mathrm{m}^{3}\right]$ is thermal capacity of the fabric and the term $b$ $\left[\mathrm{Ws}^{1 / 2} / \mathrm{m}^{2} / \mathrm{K}\right]$ presents thermal absorptivity (effusivity) of a fabric (or of any other material). The higher is thermal absorptivity of the fabric, the cooler is its feeling. In textile practice, this parameter ranges from $20 \mathrm{Ws}^{1 / 2} / \mathrm{m}^{2} / \mathrm{K}$ for fine nonwoven webs to $600 \mathrm{Ws}^{1 / 2} / \mathrm{m}^{2} / \mathrm{K}$ for heavy wet fabrics. Values $\mathrm{b}$ around $100 \mathrm{Ws}^{1 / 2} / \mathrm{m}^{2} / \mathrm{K}$ characterize warm, dry contact feeling, whereas $b$ level about $200 \mathrm{Ws}^{1 / 2} / \mathrm{m}^{2} / \mathrm{K}$ present standard, average thermal contact feeling. The $\mathrm{b}$ value can be reduced by carding and brushing of fabrics, smooth or enzymatically treated fabrics exhibit cooler or cold feelings. However, thermal contact feelings disappear within several seconds, and when these transient feelings are measured on thin fabrics, then even fabrics with a warm feeling practically cannot provide significant thermal insulation. ${ }^{12}$

Contrary to thermal absorptivity, thermal resistance, $\mathrm{R}\left[\mathrm{m}^{2} \mathrm{~K} / \mathrm{W}\right]$ is a commonly known steady state parameter of thermal insulation and it depends on fabric thickness $\mathrm{h}$ and its thermal conductivity $\lambda$ $[\mathrm{W} / \mathrm{m} / \mathrm{K}]$, as follows:

$$
\mathrm{R}=\mathrm{h} / \lambda
$$

As already mentioned, thin fabrics like shirts exhibit very low thermal resistance, that is why the knowledge of their thermal resistance is useless. They role in the clothing system depends in separation of two air layers (close to skin and outside the shirt), thermal resistance of which can be much higher than that of a shirt. One of the commercial instruments to measure thermal absorptivity of textiles and other non-homogeneous flat compressible materials is the ALAMBETA. It also measures the fabrics thickness and its thermal resistance.

\section{Conclusion}

Despite great progress in the area of design and evaluation of functional clothing with enhanced comfort properties achieved in recent decade, there are still many unsolved problems namely in the area of instrumental testing of these properties. In the paper, some of these problems were discussed, in order to inspire textile designers and researchers Analysis of other open problems will follow.

\section{Acknowledgments}

None.

\section{Funding}

None.

\section{Conflicts of interest}

The authors have no conflicts of interest regarding the publication of this paper.

\section{References}

1. Matusiak M. Thermal insulation properties of single and multilayer textiles. Fibres \&Textiles in Eastern Europe. 2006;14(5):98-112.

2. Richards MGM, Rossi $\mathrm{R}$, Meinander $\mathrm{H}$, et al. Dry and wet heat transfer through clothingdependent on the clothing properties under cold conditions, internat. $J$ of Occupational Safety and Ergonomics. 2008;14(1):69-76.

3. ISO 11092. Textiles-physiological effects - measurement of thermal and water-vapour resistance under steady-state conditions (sweating guardedhotplate test). 1993 . 
4. Bogusławska-Baczek M, Hes L. Effective water vapour permeability of wet wool fabrics and blended fabrics. Fibres \& Textiles in Eastern Europe. 2013;21(1):67-71.

5. Ren Y, Ruckman JE. Water vapour transfer in wet waterproof breathable fabrics. J of Industrial Textiles. 2003;32(3):165-175.

6. Hes L, Boguslawska Baczek M. Analysis and experimental determination of effective water vapour permeability of wet woven fabrics. JTATM. 2014;8(4):1-7

7. Mangat MM, Hes L, Bajzík V. Thermal resistance models of selected fabrics in wet state and their experimental verification. Text Res J. 2015;85:200-210.

8. Akcagun E, Boguslawska-Baczek M, Hes L. Thermal insulation and thermal contact properties of wool and wool/PES fabrics in wet state. $J$ Nat Fibers. 2019;16:199-208.
9. Matusiak M, Fracczak L. Comfort-related properties of seersucker fabrics in dry and wet state. Int J Cloth Sci Technol. 2017; 29:366-379.

10. Hes L, Tesinova P. Why skin model testers of thermal comfort of fabrics sometimes display negative values of thermal resistance? Dresden: Denkendorf International Textile Conference; 2016.

11. Hes L. Thermal properties of nonwovens. Genf 1987, Congress INDEX $87 ; 1897$.

12. Mangat AE, Hes L, Bajzik V, et al. Thermal absorptivity model of knitted rib fabric and its experimental verification. Autex Res J. 2018;18:21-27. 